\title{
REVITALISASI INTERIOR ISTANA GEBANG SEBAGAI MUSEUM BUNG KARNO DI KOTA BLITAR
}

\author{
Henggar Idham Rizky Prihartono Putra', JokoBudiwiyanto² \\ ${ }^{1}$ Program Studi S-1 Desain Interior \\ Fakultas Seni Rupa dan Desain Institut Seni Indonesia (ISI) Surakarta \\ E-mail: henggarprihartono@gmail.com \\ ${ }^{2}$ Program Studi S-1 Desain Interior \\ Fakultas Seni Rupa dan Desain Institut Seni Indonesia (ISI) Surakarta \\ E-mail: jokobudi@isi-ska.ac.id
}

\begin{abstract}
Revitalization interior Istana Gebang as Museum in Kota Blitar Bung Karno aim of building an interior design that can meet the needs of visitors to be active are education and recreation in a safe and comfortable. Interior theme used was Indis with a touch of Blitar shown in the present. Bung Karno Museum in Kota Blitar is a building that serves serve society and its development, open to the public, which is in charge of collecting, preserving, researching, communicating, showing evidence of material first president of Indonesia, Sukarno, for the purposes of study, education and enjoyment. Activities that exist in museums in Kota Blitar Bung Karno is a venue information center about Sukarno, Sukarno history disclosure from time to time. To achieve the goals need to use the approach function, ergonomics and aesthetic. Methods of data collection include literature studies, interviews, and observations. The analytical method used is the interactive method. So the result of revitalization include several space is space lobby, introduction, showrooms, libraries and audiovisual.
\end{abstract}

Keywords: Revitalization, Istana Gebang, Museum, facilities, and Localities Blitar.

\section{PENDAHULUAN}

Kota Blitar dapat dikatakan sebagai titik awal dan titik akhir Ir. Soekarno karena di Kota Blitar Bung Karno hidup di masa kecil dan di Kota Blitar pula jasadnya dimakamkan. Berbagai kenangan penduduk yang menyangkut kehidupan Bung Karno bangkit kembali di kala muncul "Peringatan Satu Abad Bung Karno" yang di pusatkan di kota Blitar. Banyak sekali kenangan Bung Karno yang terukir di Kota Blitar,seperti kebiasaan beliau pada sore hari yang suka jalan-jalan di Kebon Rojo dan keluar masuk kampung Bendogerit. Sepanjang perjalanan selalu diikuti anakanak dan remaja, sambil bernyanyi-nyanyi dan senda gurau. Semakin lama pengiring yang menjadi "pasukan kecil" Bung Karno itu semakin banyak. Acara santai demikian biasanya diakhiri sampai di ndalem gebang/ rumah Bung Karno menjelang matahari terbenam. Istana Gebang merupakan rumah tinggal orang tua Bung Karno. Letaknya tak terlalu jauh dari makam Bung Karno, lokasinya berada di Jl. Sultan Agung No.59, Kota Blitar.Rumah Soekarno saat remaja, masih terawat dan kini menjadi milik Pemerintah Kota Blitar karena telah dibeli dari ahli waris keluarga 
kakak kandung Soekarno bernama Sukarmini Wardojo senilai Rp35 miliar pada tahun 2011 lalu dan kini dibuka untuk umum yang ingin bernapaktilas di rumah bersejarah yang sering disebut Istana Gebang. 'Sebelah kanan rumah utama terdapat Balai Kesenian, dimana dahulu digunakan sebagai tempat berekspresi bagi para seniman di Blitar. Ketika Soekarmini Wardojo masih hidup, bangunan ini juga sering digunakan untuk pementasan wayang, di dalamnya dilengkapi dengan seperangkat gamelan beserta wayang kulit milik mereka. Setiap tanggal 6 Juni, yakni tanggal kelahiran Bung Karno, rumah ini menyelenggarakan haul dan berbagai macam kesenian untuk memperingati hari jadi Bung Karno dan sebagai ajang hiburan rakyat. ${ }^{2}$

Rumah bersejarah ini mulai ditempati oleh Keluarga Bung Karno antara tahun 19171919, dibeli dari seorang warga Belanda $\mathrm{CH}$. Portier Pegawai Kereta Api di Blitar dan daribeberapa sumber lisan rumah ini dibangun beriringan dengan pembangunan stasiun Kereta Api Blitar di tahun 1884 dan sampai saat ini masih berdiri kokoh. Istana gebang di pindah tangankan kepada Ibu Wardoyo pada tahun 1936. Bangunan ini pada 1998 di pugar oleh Dewan Harian Daerah (DHD) Angkatan 1945 Provinsi Jawa Timur dan langsung diresmikan Ketua DHD Angkatan 1945 Jatim Sudjito. Dirumah inilah Bung Karno menghabiskan waktunya setiap pulang ke Blitar mengambil uang saku dan pemondokkanya serta saat-saat liburan sekolah. Sekali waktu saat pulang berlibur dan sedang berada di Wlingi mengunjungi salah satu kawannya terjebak oleh aliran lahar akibat meletusnya Gunung Kelud di tahun 1919. Maka dengan melihat Istana Gebang mempunyai sejarah dan keterkaitan dengan Soekarno, perlu adanya pengembangan dan pelestarian mengenai ban-

\footnotetext{
1 BadanPerencanaan Pembangunan Daerah Kota Blitar, Profil Kota Blitar (Kota Blitar: 2012) Hal 38

2 http://www.eastjava.com/tourism/blitar/ina/ gebangpalace.html(Diaksespada Kamis, 12 Juni 2015, pukul 19:25 WIB)
}

gunan Istana Gebang menjadi sebuah museum.

Menurut International Council of Museums ( ICOM), museum adalah institusi permanen/ lembaga permanen, yang melayani kepentingan masyarakat dan kemajuannya, terbuka untuk umum, tidak bertujuan untuk mencari keuntungan, dengan cara mengumpulkan (pengoleksian), memelihara (konservasi), meneliti, memamerkan, dan mengkomunikasikan benda-benda nyata material manusia dan lingkungannya, untuk tujuan studi, pendidikan, danrekreasi.

Dalam menunjang usaha tersebut, maka haruslah dimulai dengan usaha pemeliharaan sebagai salah satu cara melestarikannya. Revitalisasi adalah merubah tempat dengan fungsi baru agar lebih sesuai dan tidak memerlukan perubahan fisik drastis. ${ }^{3}$ Revitalisasi secara umum dididefinisikan kegiatan pemugaran bangunan gedung dan lingkungan yang bersasaran untuk mendapatkan nilai tambah yang optimal secara ekonomi, sosial dan budaya. Hal ini merupakan wujud revitalisasi kawasan kota lama untuk mencegah hilangnya aset-aset anak bangsa dan kota Blitar yang bernilai sejarah karena kawasan tersebut mengalami penurunan produktifitas. Menghidupkan kembali kawasan koservasi dengan kemungkinan memfungsikan baru tanpa meninggalkan jiwa tempat (spirit of space). ${ }^{4}$

Untuk mencapai misi sasaran yang diinginkan, Pembangunan Jangka Panjang Kota Blitar dalam pengembangan pariwisata diarahkan:

1. Menguatkan predikat Kota Blitar sebagai Kota Pariwisata Sejarah

3 Sidharta, EkoBudiharjo, KonservasiLingkungandanBangunanKunoBersejarah di Surakarta,(Yogyakarta:UGM Press, 1989), Hal 11

4 BadanPerencanaan Pembangunan Daerah Kota Blitar, Master Plan Istana Gebang Kota Blitar (Kota Blitar : 2012) Hal 32 
Untuk menguatkan predikat kota Blitar sebagai Kota pariwisata sejarah, maka program pembangunan lima belas tahun kedepan diarahkan kepada upaya:

a. Mereaktualisasikan predikat Kota Blitar sebagai laboratorium kebangsaan dan pusat penumbuhkembangan kembali semangat nasionalisme Indonesia.

b. Merevitalisasi pengelolaan pariwisata daerah melalui pengembangan obyek wisata daerah terutama yang bernuansakan sejarah dan pendidikan, peningkatan sarana dan prasarana kepariwisataan, peningkatan kerjasama pariwisata lintas wilayah dan penerapan sistem pengembangan wisata yang terpadu dan berlanjut. ${ }^{5}$

c. Rencananya nama Istana Gebang akan diubah menjadi Museum Bung Karno ditargetkan menjadi museum sejarah terbesar di Asia Tenggara. ${ }^{6}$

Pemerintah Kota Blitar, Jawa Timur, akan meminta bantuan anggaran dari dana APBN untuk memugar kompleks Istana Gebang, rumah masa kecil Presiden Bung Karno, menjadi bangunan museum. Menurut Samanhudi selaku walikota kota Blitar menjelaskan bahwa di Museum Bung Karno nanti secara khusus akan dipajang benda-benda dan peninggalan yang terkait kehidupan Bung Karno sejak masa kecil sampai akhir hayatnya. Banyak benda dan barang peninggalan Bung Karno yang tersebar di mana-mana sehingga Pemkot Blitar akan berusaha mengumpulkannya di museum tersebut. Usaha menghimpun peninggalan Bung Karno tersebut tentu membutuhkan biaya yang tidak sedikit sehingga Pemkot Blitar perlu meminta tambahan anggaran dari APBN. Selain itu, pemindahan barang ke Blitar dipastikan juga

5 BadanPerencanaan Pembangunan Daerah Kota Blitar, RencanaIndukPengembanganPariwisataDaerah,TinjauanKebijakan (Kota Blitar : 2012) Hal 3

6 BadanPerencanaan Pembangunan Daerah Kota Blitar, RencanaIndukPengembanganPariwisataDaerah,GambaranUmum (Kota Blitar : 2012) Hal 23 membutuhkan biaya yang tidak sedikit. .

Istana Gebang mempunyai peran penting bagi sejarah nasional, untuk itu kawasan tersebut telah ditetapkan sebagai cagar budaya dan hal ini merupakan wujud dalam pengembangan pariwisata di Kota Blitar (Keputusan Walikota Blitar No : 188/33/HK/410.010/22011 tentang Penetapan Kawasan Cagar Budaya "Istana Gebang" Sebagai Lokasi Pembebasan Lahan Pemerintah Kota Blitar). Dengan adanya surat keputusan itu, maka kepemilikan komplek Istana Gebang telah berganti dari keluarga Ir. Soekarno kepada Pemerintah Kota Blitar akhir tahun 2011. Oleh karena itu Pemerintah Kota Blitar berencana akan membuka kawasan tersebut sebagai bahan belajar bagi masyarakat Indonesia pada khususnya, serta wisatawan mancanegara pada umumnya yang ingin mempelajari tentang sejarah bangsa Indonesia melalui kewibawaan serta kepemimpinan Bung Karno dalam membangun bangsa Indonesia ${ }^{8}$

Kondisi existing bangunan Istana Gebang yang merupakan bangunan Indis tidak menutup kemungkinan akan diangkat kembali dengan beberapa pengembangan desain. Dalam rancangan revitalisasi Istana Gebang ini juga tidak lepas dari kearifan lokal budaya Blitar antara lain Candi Penataran, Makam Bung Karno , Tari Jaranan dan Batik Tutur. Mengingat kearifan lokal Blitar sangat beragam maka dipilih salah satu yaitu batik tutur. Batik tutur merupakan penamaan batik yang dikembangkan di Blitar berdasarkan koleksi batik Asal Blitar Museum Leiden Belanda yang dibuat sekitar 1902. Penamaan batik tutur karena motif-motifnya merupakan pesan moral (pitutur) yang ingin disampaikan oleh pengrajin kepada pemakain-

\footnotetext{
7 http://regional.kompas.com/ $\mathrm{read} / 2010 / 11 / 28 / 09013693 /$ Istana.Gebang.Jadi.Museum. Bung.Karno-4 (Diaksespada Kamis,21 Mei 2015, pukul 19:25 WIB)

8 BadanPerencanaan Pembangunan Daerah Kota Blitar, Master Plan Istana Gebang Kota Blitar (Kota Blitar : 2012) Hal 1
} 
ya. ${ }^{9}$ Merujuk dari referensi di atas maka dalam revitalisasi ini diangkat sebuah tema yaitu Indis dengan sentuhan Blitar, dimana batik tutur merupakan batik khas Blitar. Adapun perancangan ini untuk mewadai beberapa kebutuhan yaitu pameran tentang Soekarno dari masa ke masa, pameran karya soekarno sebagai arsitek atau yang lainnya, dan menyimpan buku-buku tentang Soekarno. Selain itu, dalam konsep pengembangan Istana Gebang, juga diharapkan dapat memberikan kontribusi secara ekonomi, baik pada Pemerintah Kota Blitar dan masyarakat sekitar. Metode desain yang menggunakan proses desain meliputi input, sintesa dan output. Input berupa data literatur, lapangan, dan wawancara. Sintesa melalui proses analisis desain, output berupa hasil desain. Pendekatan yang digunakan adalah pendekatan fungsi, ergonomi, dan estetis. Analisa desain mengambil ide perancangan dari kondisi existing Istana Gebang yang merupakan bangunan indis dan ditambahkan unsur lokalitas Kota Blitar, kemudian dimasukkan kedalam desain interior museum Bung Karno dalam konteks revitalisasi.

\section{Ide Perancangan}

Proses kolonialisme VOC sampai dengan pemerintahan Belanda dalam kurun waktu yang lama menghasilkan budaya campuran. Kebudayaan Indis adalah akibat dari pertemuan dan pencampuran peradaban Jawa dan Eropa (Belanda), yang melahirkan kebudayaan campuran (budaya gado - gado bazaar culture). ${ }^{10}$ Arsitektur dan interior Indis hadir sebagai jawaban dari orang - orang pemerintahan Belanda yang

9 Roctri Agung Bawono, dkk, Batik Tutur Blitar: Transformasi Pesan Moral Dari Dinding Candi Menjadi Sehelai Kain dalam http://erepo.unud.ac.id37891b9070206f3159a6d437beded209a89c7.pdf (Diakses pada Kamis ,29 Desember 2016, pukul 19:25 WIB)

10 DjokoSoekiman, dalam Dhian Lestari Hastuti "Interior DalempadaRumahSaudagar Batik Laweyan di Awal Abad ke-20 KajianEstetika." Tesisuntukmencapaiderajatsarjana S-2 (Surakarta : Institut Seni Indonesia Surakarta)., 2009, 18-19. hidup di Hindia Belanda dengan iklim tropis. Arsitektur dan interior Indis merupakan bagian dari gaya hidup Indis yang mengalami masa kejayaan di awal abad ke-20. ${ }^{11}$

Djoko Soekiman juga membahas detail mengenai konsep keindahan rumah Indis tersebut:

Berkaitan dengan ragam hias sebagai kelengkapan ruang yang bernilai estetis, panel-panel daun pintu dipahat sangat halus, dengan ragam hias berupa tumbuh-tumbuhan berselang-seling, dan berbeda-beda dengan ukir krawang (a'jour relief). Hal ini dapat dipergunakan untuk petunjuk bahwa rumah seseorang adalah orang miskin apabila pintu-pintunya tanpa di beri panel berukir indah. Di ruang tengah yang terletak dibelakang ruang depan disebut voorhuis, dinding-dindingnya digantungkan lukisan-lukisan sebagai hiasan disamping-sampingnya terdapat piring-piring hias serta jambangan dari porselin. ${ }^{12}$

Kemegahan rumah tinggal masyarakat indis yang mampu lebih diperkaya dengan adanya perabotan rumah yang penuh hiasan, yang dipelitur warna hitam, serta dicat warna merah menyala, coklat atau hijau dan emas. Warna-warna tersebut sangat kontras dengan warna dinding yang dilepa halus. Hiasan yang lain sebagai bentuk nilai keindahan adalah terdapatnya barang-barang porselin, dan lebih semarak lagi terdapatnya cermin-cermin berukuran besar, serta tempat lilin yang berukir. Demikian halnya dari kusen pintu dan jendela yang berwarna keemasan, sangat menyedapkan pandangan mata. ${ }^{13}$

11 Dhian Lestari Hastuti "Interior

DalempadaRumahSaudagar Batik Laweyan di Awal Abad ke-20 KajianEstetika." Tesisuntukmencapaiderajatsarjana S-2 (Surakarta : InstitutSeni Indonesia Surakarta)., 2009, 70.

12 DjokoSoekiman, 2000, 139-140

13 DjokoSoekiman, 147 
Revitalisasi interior Istana Gebang sebagai Museum Bung Karno ini berada di Kota Blitar yang memiliki berbagai macam variasi karya seni yang menarik diantaranya Batik Tutur yang merupakan batik Blitar. Batik Tutur adalah batik ciptaan Dewan Kesenian Blitar. Hingga saat ini, batik yang berasal dari Blitar dan sekitarnya yang berumur tua hanya ditemukan di Museum Leiden Belanda dengan penamaan Batik Afkomstig Uit Blitar tahun 1902 yang corak dan ragamnya berbeda dengan batik pada umumnya di sentra-sentra budaya batik di Nusantara. Batik tersebut berhiaskan ragam tumbuhan dan binatang singa, burung, ayam, kuda terbang, serta kupu-kupu yang kemungkinan memiliki pesan moral yang tersembunyi. Keberadaan batik Blitar di Museum Laiden tersebut baru disadari oleh masyarakat di Blitar pada tahun 2007 sehingga diberikan nama batik tutur oleh Wima Brahmantya sebagai orang pertama yang menggunakan istilah tersebut. Kata tutur berasal dari istilah pitutur yang berarti pesan atau nasehat, sehingga batik tutur memiliki pengertian suatu batik yang mengandung pesan moral (nasehat) berdasarkan motif yang ditutur-kan (dibaca dan diucapkan).

Batik Blitar yang menjadi koleksi $\mathrm{Mu}-$ seum Leiden hingga saat ini tidak ada keterangan yang menjelaskan lebih detail terkait pesan moral yang digambarkan dalam motif-motif tersebut. Menurut budayawan di Blitar penggambaran motif binatang dan tumbuhan tersebut merupakan sindiran kepada bangsawan-bangsawan bentukan Belanda yang tidak membela masyarakat miskin. Terbentuknya batik Blitar tersebut diperkirakan merupakan hasil ekspoitasi pengetahuan dan pemahaman sebelumnya tentang kekayaan budaya yang dimiliki. ${ }^{14}$ Adapun yang meng-

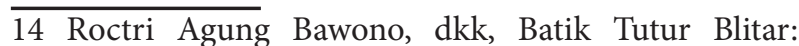
Transformasi Pesan Moral Dari Dinding Candi Menjadi Sehelai Kain dalam http://erepo.unud.ac.id37891b9070206f3159a6d437beded209a89c7.pdf (Diakses pada gambar ulang motif batik ini adalah Edi Dewa. Batik Tutur ini resmi dipublikasikan di masyarakat pada 5 Februari 2012 dengan dasaran supaya batik Afkomstig Uit Blitar dapat kembali ke tengah masyarakat Blitar sehingga masyarakat Blitar tahu dan memahami bahwa sebenarnya Blitar memiliki batik kuno yang sudah lama hilang. Penggambaran ulang motif batik ini dilakukan oleh seorang seniman lukis lokal Blitar yang bernama Edi Dewa, beliau dengan rekan-rekan DKKB merasa tergugah untuk me-reka ulang motif batik Afkomstig Uit Blitar menjadi motif batik Tutur khas Blitar lengkap dengan sesanti dan tutur yang terkandung didalamnya.

Motif reka-an yang paling awal dibuat adalah motif batik tutur Gambir sepuh yang kemudian menghasilkan motif- motif lain diantaranya batik Cinde Gading, batik Simo Samaran, batik Pedut Kelud, batik Awu Nanas, batik Celeret Dubang, batik Mupus Pupus, batik Galih Dempo, batik Mirong Kampuh Jinggo, yang semua sumber ide nya berasal dari batik Afkomstig Uit Blitar. ${ }^{15}$
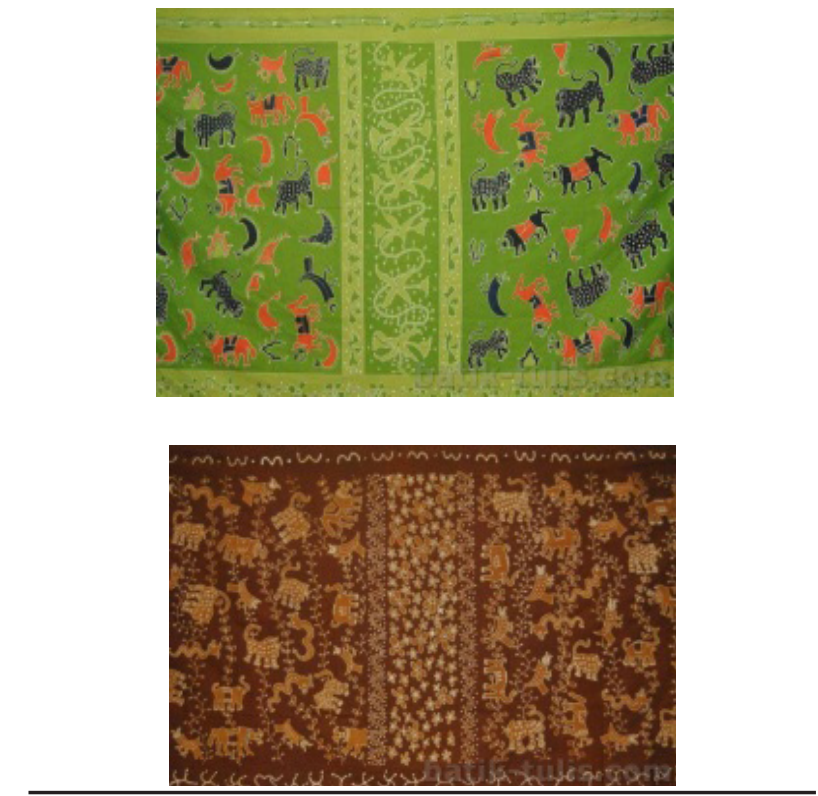

Kamis ,29 Desember 2016, pukul 19:25 WIB)

15 http://ejournal.unesa.ac.id/article/14088/49/article. pdf (diunduhtanggal 9 Agustus 2016) 
Gambar 1 : batik tutur Cinde Gading dan Mumus Pupus ( Sumber : http://batik-tulis.com/blog/batik-blitar )
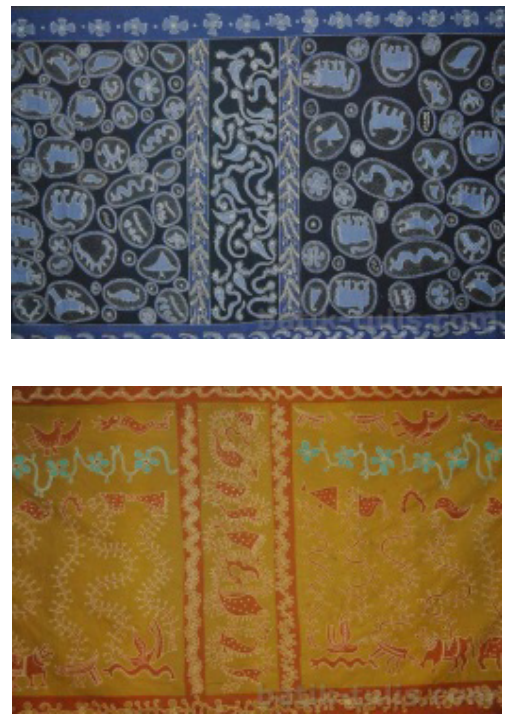

Gambar 2 : batik tutur Pedut Kelud dan Ganbir Sepuh ( Sumber : http://batik-tulis.com/blog/batik-blitar )

\section{a. Konsep Lantai}

Penggunaan material tegel motif dengan kombinasi teraso yang merupakan kondisi eksisting lantai saat ini. Untuk penggunaan material teraso 20x20 tetap dipertahankan karena mengingat Istana Gebang merupakan bangunan cagar budaya, namun akan di kombinasi dengan tegel motif yang dapat memperkuat citra indis. Material tegel motif 20x20 ini diadopsi dari lantai Istana Gebang yang terdahulu sebelum di pugar oleh Dewan Harian Daerah Provinsi Jawa Timur.

\section{b. Konsep Dinding}

Dinding pada rancangan kali ini tidak akan merubah secara structural mengingat hal ini dalam kontek revitalisasi. Untuk menunjang terciptanya suasana interior indis dengan sentuhan Blitar, maka penambahan panel-panel kayu pada dinding dan dikombinasikan dengan batik tutur. Batik tutur memiliki berbagai macam motif, namun akan dipilih beberapa saja yaitu
Gambir sepuh, Cinde Gading, Pedut Kelud, Mupus Pupus, dimana penerapannya menggunakan media kayu yang di batik dengan bahan dasar malam.

\section{c. Konsep Ceiling}

Kebudayaan Indis merupakan percampuran antara gaya Belanda dengan Indonesia khususnya Jawa, sehingga pada rancangan ini akan mengadopsi ceiling rumah Jawa yaitu tumpang sari. Tumpang sari memiliki bentuk berundak-undak semakin ke atas semakin menyempit, dimana spiritualitas di Jawa menyebutkan tumpangsari mengandung arti berketuhanan yang Maha Agung.

\section{d. Konsep Pengisi Ruang}

Konsep pengisi ruang yang akan dimunculkan kedalam perancangan yaitu akan menghadirkan kembali beberapa bentuk pengisi ruang yang populer pada tahun 1700-1800.
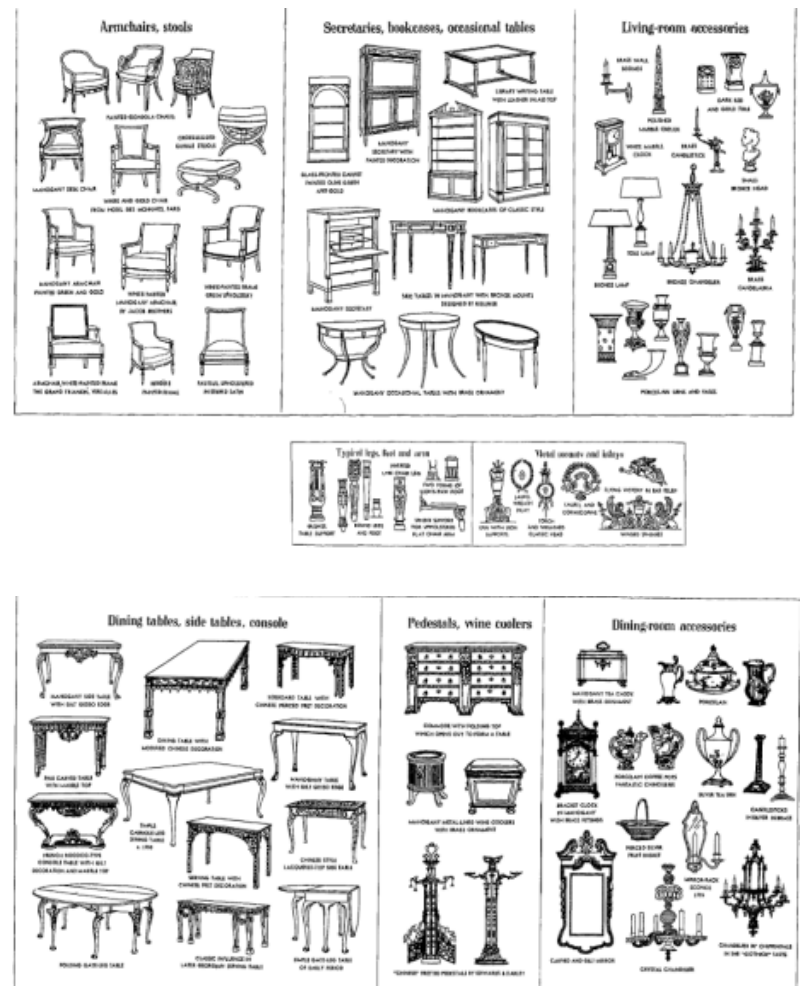

Gambar 3 : Bentuk pengisi ruang tahun 1700 1800 ( Sumber : Joseph De Chiara, Time-Saver 
Standart for Interior Design and Space Planning)

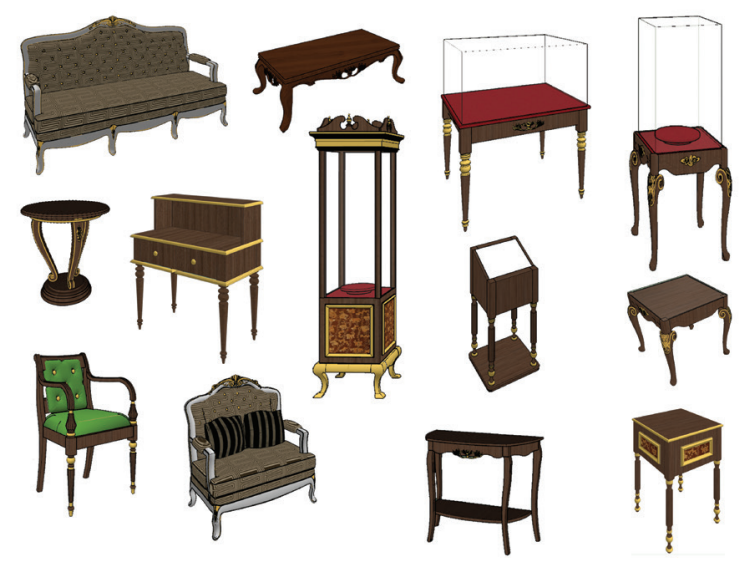

Gambar4 : Hasil desain furniture terpilih

Museum Bung Karno di Kota Blitar dapat dikategorikan sebagai museum khusus yang dikelola oleh pemerintah. Cabang ilmu yang menjadi sumber materi koleksi museum ini adalah ilmu sejarah (kehidupan Bung Karno). Dari materi koleksi dan cara penyajian koleksinya, museum Bung Karno di Kota Blitar termasuk sebuah museum ilmu pengetahuan yang menggunakan presentasi estetis dalam mengkomunikasikan informasi tentang sejarah kehidupan seorang Negarawan (Bung Karno). Dalam upaya membentuk visual dari perancangan tersebut tidak menutup kemungkinan adanya perpaduan bangunan asli dengan penambahan unsur lokalitas, maka dipilih tema Indis dengan sentuhan Blitar. Selain itu, metode penyampaian berupa pameran di museum adalah salah satu bentuk penyajian informasi tentang benda koleksi yang dimiliki museum. $\mathrm{La}$ belling merupakan salah satu teknik penyajian materi pamer dalam memberikan informasi oleh museum kepada pengunjung. ${ }^{16}$ Membuat label perlu direncanakan secara benar mengingat museum ini didatangi bukan pengunjung domestik saja, melainkan mancanegara yang sangat berantusias. Oleh karena itu label pada

16 DepartemenPendidikan Dan Kebudayaan, DirektoratJenderalKebudayaanProyekPembinaanPermuseuman Jakarta, $1994: 20$ materi pamer akan menggunakan 2 (dua) bahasa yaitu bahasa Indonesia dan bahasa Inggris (bilingual). Benda koleksi yang dipamerkan tidak hanya diletakkan begitu saja, semua harus diatur dalam sebuah cerita atau storyline tertentu dan direncanakan agar pameran tersebut dapat dipahami pengunjung. ${ }^{17}$

\section{PEMBAHASAN}

\section{Lobby}

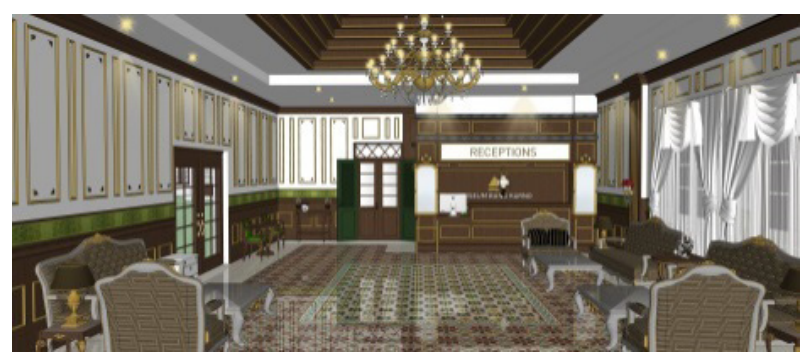

Gambar 5 : Gambar perspektif lobby Museum Bung Karno di Kota Blitar

Area lobi merupakan area publik yang merupakan pintu masuk utama serta area lalu lalang para pengunjung Museum Bung Karno. Area lobi harus menunjukkan karakter dari museum sesuai konsep ide perancangan. Lantai tegel motif dan terdapat lampu gantung robyong yang diadopsi dari lampu keraton Kasunanan Surakarta .Bentuk plafon yang menyerupai rumah Jawa yaitu tumpang sari yang di beri aksen batik tutur pada bagian tengahnya. Penggunaan panel-panel kayu yang dikombinasi dengan warna emas pada dinding disesuikan pada masa kejayaan indis di Indonesia. Namun, panel-panel pada dinding dimodifikasi dengan penambahan panel kayu yang di batik dengan motif batik tutur Blitar guna menunjang lokalitas dan tema. Furniture isian pada area lobi diadopsi dari bentuk furniture pada tahun 1800an yang dimodifikasi sedemikian rupa sehingga 17 DepartemenPendidikan Dan Kebudayaan, DirektoratJenderalKebudayaanProyekPembinaanPermuseuman Jakarta, $1994: 3$ 
tercipta pencapaian tema yang disampaikan yaitu indis dengan sentuhan Blitar.

\section{R. Introduksi}

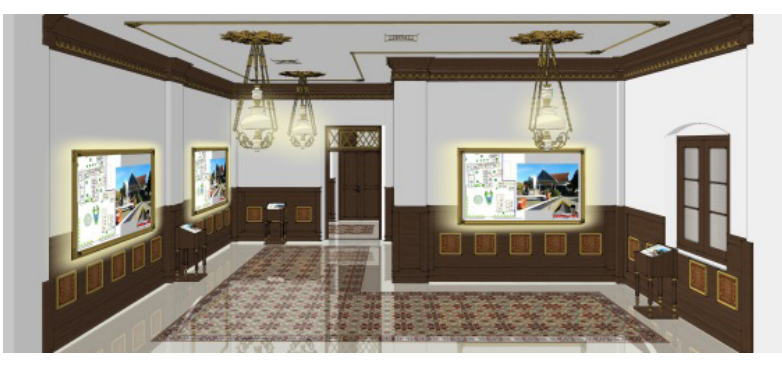

Gambar 6 : Gambar perspektif ruang introduksi Museum Bung Karno di Kota Blitar

Area Introduksi merupakan fasilitas ruang yang disediakan oleh museum yang berguna untuk mengenalkan fasilitas serta memberi gambaran akan informasi semacam apa yang akan pengunjung dapatkan pada ruangan-ruangan selanjutnya. Area introduksi harus menunjukkan karakter dari museum sesuai konsep ide perancangan. Lantai tegel motif dan terdapat lampu gantung Jawa yang merupakan bentuk lampu yang sekarang digunakan pada istana gebang. Penambahan gypsum motif ornamen berwarna emas pada plafon yang akan memperkuat citra indis. Penggunaan panel-panel kayu yang dikombinasi dengan warna emas pada dinding disesuikan pada masa kejayaan indis di Indonesia. Namun, panel-panel pada dinding dimodifikasi dengan penambahan panel kayu yang di batik dengan motif batik tutur Blitar guna menunjang lokalitas dan tema yaitu indis dengan sentuhan Blitar.

\section{R. Pamer}

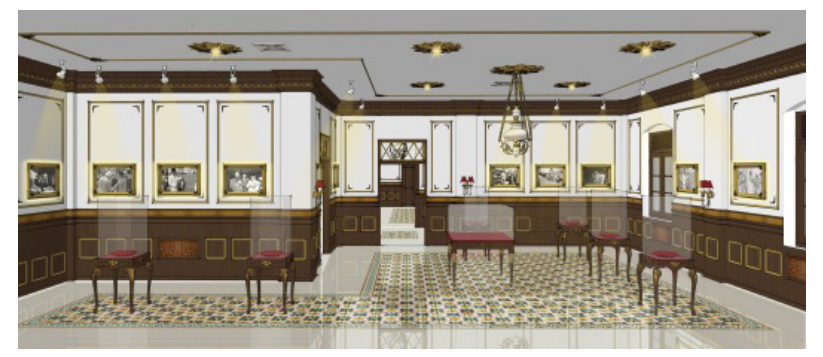

Gambar 7 : Gambar perspektif ruang pamer 1 (satu) Museum Bung Karno di Kota Blitar

Area pamer harus menunjukkan karakter dari museum sesuai konsep ide perancangan. Lantai tegel motif dan terdapat lampu gantung Jawa yang merupakan bentuk lampu yang sekarang digunakan pada istana gebang. Penambahan gypsum motif ornamen berwarna emas pada plafon yang akan memperkuat citra indis. Penggunaan panel-panel kayu yang dikombinasi dengan warna emas pada dinding disesuikan pada masa kejayaan indis di Indonesia. Namun, panel-panel pada dinding dimodifikasi dengan penambahan panel kayu yang di batik dengan motif batik tutur Blitar guna menunjang lokalitas dan tema. Furniture isian berupa vitrin dan pedestal pada area pamer diadopsi dari bentuk furniture pada tahun 1800an yang dimodifikasi sedemikian rupa sehingga tercipta pencapaian tema yang disampaikan yaitu indis dengan sentuhan Blitar.

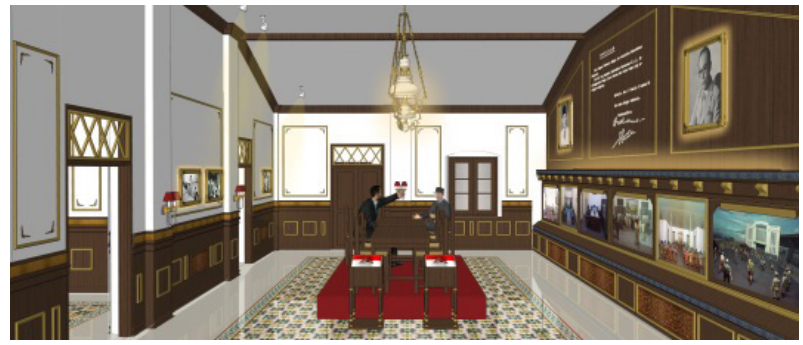

Gambar 8: Gambar perspektif ruang pamer 2 (dua) Museum Bung Karno di Kota Blitar

Informasi yang disampaikan melalui media pamer meliputi diorama yang disesuaikan dengan storyline yang dibuat dan beberapa furniture yang didisplay ulang dengan penambahan patung lilin guna menambah penciptaan suasana. Benda pamer berupa foto didisplay menggunakan pigura dengan desain khusus yang diberi pencahayaan belakang (backlight) sehingga foto terkesan timbul tetapi foto tetap diberi pencahayaan dari atas menggunakan spotlight. 


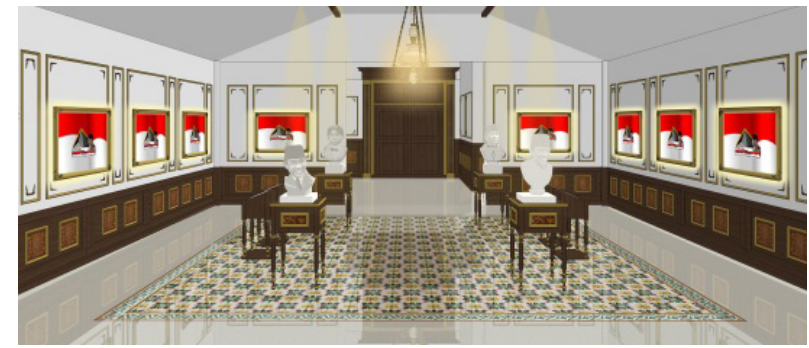

Gambar 9: Gambar perspektif area isu populer Museum Bung Karno di Kota Blitar

Museum ini didukung dengan teknologi masa kini yaitu penggunaan panel LED interaktif touchscreen . Hal ini merupakan wujud interaksi pengunjung terhadap benda yang dipamerkan pada museum. Sehingga pengunjung dapat dengan mudah memahami satu per satu benda yang dipamerkan.

\section{R. Audiovisual}

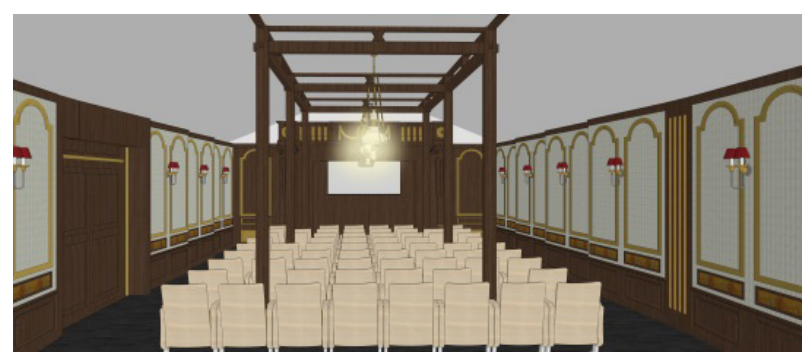

Gambar 10 : Gambar perspektif ruang audiovisual $\mathrm{Mu}-$ seum Bung Karno di Kota Blitar

Area audiovisual merupakan fasilitas ruang yang disediakan oleh museum yang berguna untuk Menambah informasi yang berkaitan dengan Soekarno dari masa ke masa dengan media gambar dan suara. Area audiovisual harus menunjukkan karakter dari museum sesuai konsep ide perancangan. Lantai menggunakan carpet yang dapat menyerap suara dan terdapat lampu gantung Jawa yang merupakan bentuk lampu yang sekarang digunakan pada istana gebang. Penggunaan panel-panel kayu yang dikombinasi dengan warna emas pada dinding disesuikan pada masa kejayaan Indis di Indonesia. Namun, panel-panel pada dinding dimodi- fikasi dengan penambahan panel kayu yang di batik dengan motif batik tutur Blitar guna menunjang lokalitas dan tema yaitu Indis dengan sentuhan Blitar.

\section{Area Perpustakaan}

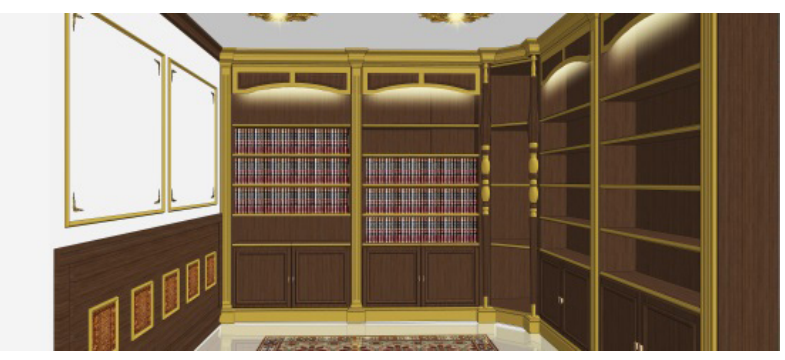

Gambar 11 : Gambar perspektif ruang perpustakaan Museum Bung Karno di Kota Blitar

Area perpustakaan harus menunjukkan karakter dari museum sesuai konsep ide perancangan. Lantai tegel motif dan penambahan gypsum motif ornamen berwarna emas pada plafon yang akan memperkuat citra Indis. Penggunaan panel-panel kayu yang dikombinasi dengan warna emas pada dinding disesuikan pada masa kejayaan Indis di Indonesia. Namun, panel-panel pada dinding dimodifikasi dengan penambahan panel kayu yang di batik dengan motif batik tutur Blitar guna menunjang lokalitas dan tema. Bentuk furniture almari buku yang di desain built-in namun tetap mempertimbangkan tercapainya sebuah tema yang disampaikan serta penggunaan indirect lamp pada furniture guna menunjang estetis.

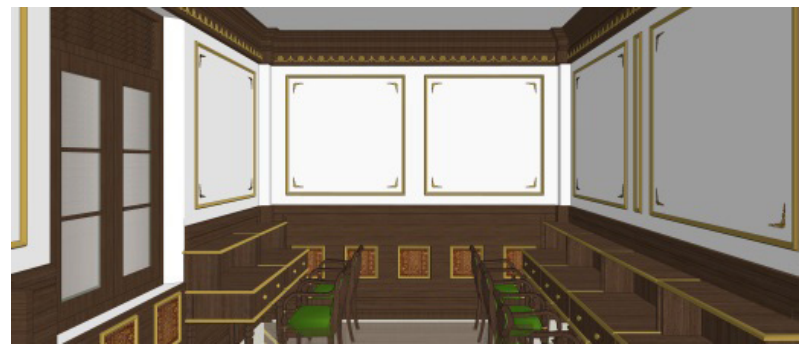

Gambar 12: Gambar perspektif ruang baca Museum Bung Karno di Kota Blitar

Treatmen yang sama juga di- 
aplikasikan pada dinding area baca dimana ada penambahan ornamen pada bawah cornice guna memperkuat Indis pada ruangan tersebut. Penggunaan furniture berupa kursi dan meja baca yang diadopsi dari bentuk furniture 1800an yang dimodifikasi dengan sedemikian rupa sehingga ruangan tersebut seolah-olah seperti ruangan pada masa kejayaan indis di Indonesia namun tetap ada sentuhan lokalitas Kota Blitar.

\section{SIMPULAN}

Museum Bung Karno di Kota Blitar adalah bangunan yang berfungsi melayani masyarakat dan perkembangannya, terbuka untuk umum, yang bertugas mengumpulkan, melestarikan, meneliti, mengkomunikasikan, memamerkan bukti-bukti bendawi presiden pertama Indonesia yaitu Soekarno, untuk tujuan studi, pendidikan dan kesenangan. Aktifitas yang ada pada museum Bung Karno di Kota Blitar adalah sebagai wadah pusat informasi tentang Soekarno, pengungkapan sejarah Soekarno dari masa ke masa .Untuk memenuhi kebutuhan aktifitas tersebut, fasilitas ruang yang dibutuhkan untuk mewadainya adalah ruang lobby, ruang introduksi, ruang pamer, ruang perpustakaan, dan ruang audiovisual.

Perancangan ini mengambil tema indis dengan sentuhan blitar. Tema tersebut dipilih dengan maksud agar dapat memunculkan kembali suasana yang mengingatkan pada kejayaan kebudayaan masyarakat Indis pada saat itu, sehingga para pengunjung yang menikmati fasilitas di dalam museum Bung Karno bisa merasakan atmosfir seperti berada pada bangunan kolonial zaman dulu, tetapi bahan dan finishing untuk pembentuk ruang, furniture serta elemen dekorasinya menggunakan bahan I finishing zaman sekarang.

Dengan sentuhan Blitar dimaksudkan karena letak bangunan berada di kota Blitar sehingga tidak menutup kemungkinan untuk memunculkan unsur lokalitas dan identintitas dari daerah tersebut. Oleh karena itu dipilih batik tutur yang diolah kembali dengan sedemikian rupa sebagai penambahan elemen estetis pada musem Bung Karno di Kota Blitar.

\section{DAFTAR PUSTAKA}

Badan Perencanaan Pembangunan Daerah Kota Blitar, Master Plan Istana Gebang Kota Blitar (Kota Blitar : 2012)

Badan Perencanaan Pembangunan Daerah Kota Blitar, Profil Kota Blitar (Kota Blitar : 2012)

Badan Perencanaan Pembangunan Daerah Kota Blitar, Rencana Induk Pengembangan Pariwisata Daerah, (Kota Bli$\operatorname{tar}:$ 2012)

Ching, Francis.D.K., "Ilustrasi Desain Interior", Jakarta : Erlangga, 1996.

Departemen Pendidikan Dan Kebudayaan, Direktorat Jenderal Kebudayaan Proyek Pembinaan Permuseuman Jakarta, 1994

Departemen Pendidikan Nasional, Kamus Besar Bahasa Indonesia, ed. 3, Jakarta : Balai Pustaka, 2001

Dharsono, Sunarmi, Estetika Seni Rupa Nusantara, Surakarta, ISI Press, 2007

Hastuti Dhian Lestari "Interior Dalem pada Rumah Saudagar Batik Laweyan di Awal Abad ke-20 Kajian Estetika.", Tesis untuk mencapai derajat sarjana 
S-2 Progaram Studi Pengkajian Seni Minat Seni Rupa, Surakarta : Institut Seni Indonesia Surakarta, 2009

Kartika Dharsono Sony, Pengantar Estetika, Bandung, Rekayasa Sains, 2004

Neufert Ernst, Data Arsitek Jilid 2 :Jakarta, Erlangga, 1992

Panero Julius, Martin Zelnik, Human Dimension,Jakarta:Erlangga,2003

Sidharta,Eko Budiharjo, Konservasi Lingkungan dan Bangunan Kuno Bersejarah di Surakarta,(Yogyakarta:UGM Press, 1989)

Suma’mur P.K, “Ergonomi untuk Produktivitas Kerja", Jakarta : CV Haji Masagung, 1989.

Sunarmi, "Ergonomi dan Aplikasinya Pada Kriya”, Surakarta: STSI Surakarta, 2001.

Sunarmi, Metodologi Desain, Surakarta: Jurusan Seni Rupa Program Studi Desain Interior, Institut Seni Indonesia Surakarta,2008

Sunarmi, "Modul Mata Kuliah Desain Interior III”, Surakarta: STSI Surakarta, 2007.

Suptandar J. Pamudji, "Desain Interior Pengantar Merencana Interior Untuk Mahasiswa Desain dan Arsitektur", Jakarta : Djambatan, 1999.

\section{Sumber Internet :}

http://www.eastjava.com/tourism/blitar/ina/ gebangpalace.html(Diakses pada Ka- mis,12 Juni 2015, pukul 19:25 WIB)

http://ibrary.binus.ac.id/eColls/eThesisdoc/

Bab2/2011-2-00956-DI\%20Bab2001. pdf(Diaksespada Kamis,12 Juni 2015, pukul 1:34 WIB)

h t t p:// regional.kompas.com/ $\mathrm{read} / 2010 / 11 / 28 / 09013693 /$ Istana. Gebang.Jadi.Museum.Bung.Karno-4 (Diakses pada Kamis,21 Mei 2015, pukul 19:25 WIB)

http://ejournal.unesa.ac.id/article/14088/49/ article.pdf ( diunduhtanggal 9 Agustus 2016)

Roctri Agung Bawono, dkk, Batik Tutur Blitar: Transformasi Pesan Moral Dari Dinding Candi Menjadi Sehelai Kain dalam http://erepo.unud. ac.id37891b9070206f3159a6d437beded209a89c7.pdf (Diakses pada Kamis ,29 Desember 2016, pukul 19:25 WIB)

Keputusan Menteri Kebudayaan dan Pariwisata, Nomor : KM.33/PL.303/ MKP/2004 Tentang Museum. dalamhttp://lib.ui.ac.id/file?file=digital/132800-T\%2027812-Peran\%20 museum-Pendahuluan.pdf (diaksespada 6 September 2016 pukul 00.05 wib)

\section{Narasumber :}

Bambang In Mardiono, umur 70 tahun, Istana Gebang, jurubicara Istana GebangdanSejarahwan Kota blitar.(pada 21 Maret 2015, pukul 14:44 WIB 